\title{
Chemical composition and in vitro biological activities of cardoon (Cynara cardunculus L. var. altilis DC.) seeds as influenced by viability
}

\author{
Filipa Mandim ${ }^{\mathrm{a}, \mathrm{b}}$, Maria Inês Dias ${ }^{\mathrm{a}}$, José Pinela ${ }^{\mathrm{a}}$, Paulo Barracosa ${ }^{\mathrm{c}}$, Marija Ivanov ${ }^{\mathrm{d}}$, \\ Dejan Stojkovićd ${ }^{\mathrm{d}}$, Marina Soković ${ }^{\mathrm{d}}$, Celestino Santos-Buelga ${ }^{\mathrm{b}}$, Lillian Barros ${ }^{\mathrm{a}, *}$, \\ Isabel C.F.R. Ferreira ${ }^{\mathrm{a}, *}$ \\ ${ }^{\text {a }}$ Centro de Investigação de Montanha (CIMO), Instituto Politécnico de Bragança, Campus de Santa Apolónia, 5300-253 Bragança, Portugal \\ ${ }^{\mathrm{b}}$ Grupo de Investigación en Polifenoles (GIP-USAL), Facultad de Farmacia, Universidad de Salamanca, Campus Miguel de Unamuno s/n, 37007 Salamanca, Spain \\ ${ }^{\mathrm{c}}$ Escola Superior Agrária de Viseu, Instituto Politécnico de Viseu, Quinta da Alagoa, 3500-606 Viseu, Portugal \\ ${ }^{\mathrm{d}}$ Institute for Biological Research "Siniša Stanković"- National Institute of Republic of Serbia, University of Belgrade, Bulevar despota Stefana 142, Belgrade, Serbia
}

\section{A R T I C L E I N F O}

\section{Keywords:}

Cynara cardunculus L.

Seed viability

Chemical composition

Phenolic acids

Bioactive properties

\begin{abstract}
A B S T R A C T
Cardoon is a multi-purpose crop for several industries. In this study, cardoon seeds were separated according to the viability and characterized for their chemical composition and bioactivities. Viable seeds contained higher levels of $\alpha$-tocopherol (6.7 mg/100 g), lipids (23.11 g/100 g, manly oleic and linoleic acids), and free sugars $(5.4 \mathrm{~g} / 100 \mathrm{~g})$ than the unviable ones. The hydroethanolic extract of viable seeds presented a higher concentration of phenolic compounds, namely 5-O-caffeoylquinic $(8.0 \mathrm{mg} / \mathrm{g}$ ) and 3,5-O-dicaffeoylquinic (43.9 mg/ g) acids, and greater in vitro antioxidant activity. Both extracts showed antibacterial properties, but the best results were achieved with unviable seeds. The extracts had similar antifungal activity but did not reveal antiinflammatory capacity or cytotoxicity to the tested cell lines. Therefore, while viable seeds contained antioxidant phytochemicals and an energy and carbon source for germination, unavailable seeds stood out for their potential to be used in the development of bio-based antibacterial ingredients.
\end{abstract}

\section{Introduction}

Cynara cardunculus L., the so-called cardoon, is an herbaceous perennial diploid plant of the Asteraceae family, native to the Mediterranean Basin. This species comprises three cross-compatible forms: the cultivated cardoon (var. altilis DC.), the globe artichoke (var. scolymus (L.) Fiori), and their common ancestor, the wild cardoon (var. sylvestris (Lamk) Fiori) (Gominho, Curt, Lourenço, Fernández, \& Pereira, 2018). The cultivated cardoon is characterized by rosetteshaped leaves, consumed for its enlarged bleached petiole, large inflorescences with violet-purple flowers, sharp bracts, pappus and seeds, and a prominent stalk, which plays an essential role in wind dispersal of seeds (Gominho et al., 2018). Its vegetative annual cycle includes leaf development in autumn and winter, stem lengthening in spring, and capitulum formation in early summer. Then, in late summer, the aerial plant part becomes dry, yielding from 15.2 to $24.2 \mathrm{t} / \mathrm{ha}$ /year of biomass, depending of the annual precipitation (Fernández, Curt, \& Aguado, 2006).

The cultivated cardoon can reach around $2.5 \mathrm{~m}$ in height and has a strong and highly developed root system that allows it to explore a significant volume of soil. Additionally, its root stores fructans (fructose polymers), which is interpreted as an adaptive strategy to overcome unfavourable conditions, like drought Mediterranean environments (Raccuia \& Melilli, 2010). All these morphological and physiological characteristics of cardoon increase its potential to be grown in different locations around the world, including California, China, Mexico, and West Africa (Vergara, Ladero, García-Ochoa, \& Villar, 2018). Moreover, this field crop helps to conserve fragile Mediterranean agroecosystems due to its positive effect on soil erosion control, nutrient recycling, and soil carbon storage (Mauromicale, Sortino, Pesce, Agnello, \& Mauro, 2014).

Cardoon has been considered as a multi-purpose crop with food, pharmacological, and chemical related applications (Gominho et al., 2018). Its commercial and economic value has increased due to its environmentally friendly industrial uses, including the production of lignocellulosic biomass and seeds (achenes) for energy (solid biofuel, biodiesel, and biomethane), paper pulp, lightwood panels (Barracosa, Rosa, Barros, \& Pires, 2018), and food ingredients/products (milk

\footnotetext{
* Corresponding authors.

E-mail addresses: lillian@ipb.pt (L. Barros), iferreira@ipb.pt (I.C.F.R. Ferreira).
} 

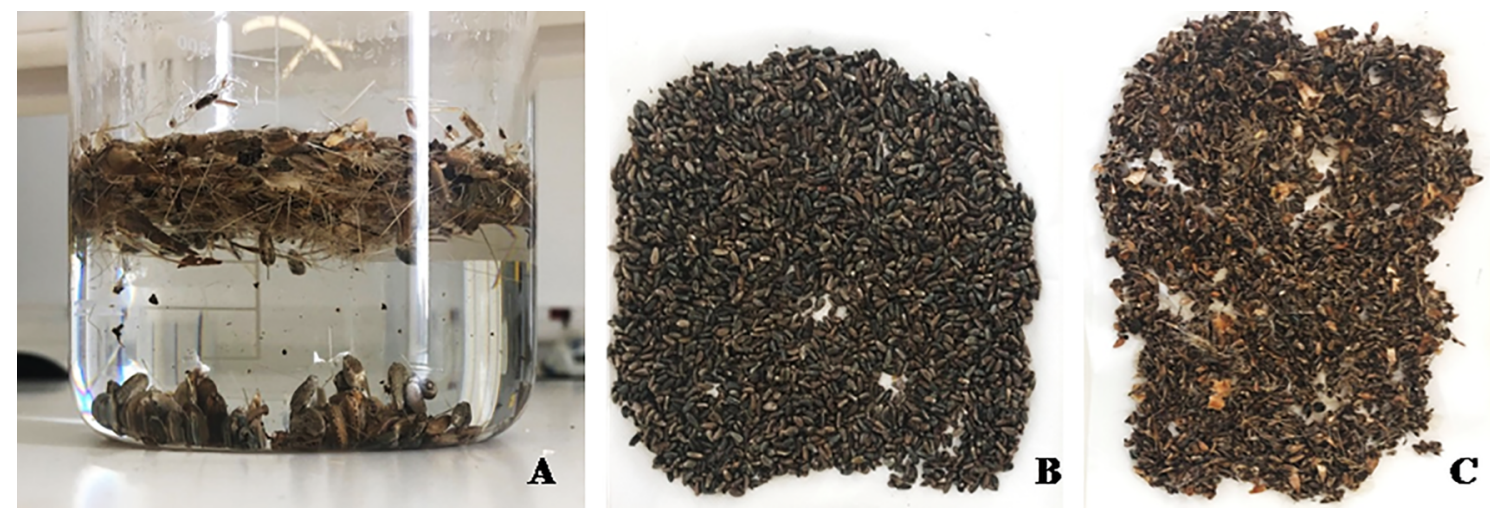

Fig. 1. Illustration of the float test used for separation of $C$. cardunculus seeds (A) into viable (B) and unviable (C) seeds.

coagulants for cheese making and edible oil) (Gominho et al., 2018). It is also traditionally used in the treatment of liver diseases and dyspepsia, as well as diuretic, hypocholesterolemic, and liver tonic (de Falco, Incerti, Amato, \& Lanzotti, 2015). According to the literature, cardoon contains compounds with bioactive properties, such as chlorogenic acids (caffeoylquinic acids, namely cynarin), flavonoids (luteolin, apigenin, and naringenin), and anthocyanins (cyanidin, delphinidin, and peonidin), which could be related to the health-promoting effects associated with this plant (de Falco et al., 2015; Petropoulos et al., 2019). Indeed, significant antimicrobial (Dias et al., 2018; Petropoulos et al., 2019; Scavo et al., 2019), anti-inflammatory (Kammoun et al., 2010), cytotoxic (Petropoulos et al., 2019; Ramos et al., 2017), and antioxidant (Petropoulos, Pereira, Ntatsi, et al., 2018; Petropoulos, Pereira, Tzortzakis, Barros, \& Ferreira, 2018; Petropoulos et al., 2019) activities were already attributed to extracts obtained from different parts of cardoon.

In recent years, the use of cultivated cardoon has also become increasingly popular due to its composition in nutrients and health-promoting compounds. Cultivated cardoon is cropped as an annual plant, and raised from seed and vegetative (FAO, 2019). However, its germination is affected by the seeds viability and quality, which also may affect the uniformity of development, yield and quality of the harvested product, as well as its potential for commercialization (Xia, Xu, Li, Zhang, \& Fan, 2019). To take complete advantage of its potential, including the most diverse forms of biomass, it is essential to ensure the seed quality to the maintenance of its sustainable production system, as well as better understand the extent of unviable seeds and the influence in the profitability and germination characteristics.

To the best of the authors' knowledge, the viability effects on quality attributes of cardoon seeds has never been evaluated. There is only a study reporting that the number of seeds per flower head and the size of the seeds, which is influenced by the insertion order of the capitulum on the main stem (Piluzza, Molinu, Re, \& Sulas, 2019). Therefore, this study was performed to characterize the chemical composition (tocopherols, fatty acids, organic acids, free sugars, and phenolic compounds) and the in vitro biological activities (antioxidant, cytotoxic, anti-inflammatory, and antimicrobial) of viable and unviable cardoon seeds. The results can be applied to the implementation of methodologies to improve the cardoon seed quality, as well as to add value to the unviable ones.

\section{Material and methods}

\subsection{Standards and reagents}

HPLC-grade formic acid and acetonitrile were supplied by Fisher Scientific (Lisbon, Portugal). The fatty acid methyl ester (FAME) mixture (standard $47885-\mathrm{U}$ ), standards of sugars and organic acids, acetic acid, sulphorhodamine $\mathrm{B}$, trolox (6-hydroxy-2,5,7,8- tetramethylchroman-2-carboxylic acid), 2,2'-azobis(2-methylpropionamidine) dihydrochloride (AAPH), ellipticine, trichloroacetic acid, trypan blue, and tris(hydroxymethyl)aminomethane were acquired from Sigma-Aldrich (St Louis, MO, USA). Standards of phenolic compounds were obtained from Extrasynthèse (Genay, France). Tocol $(50 \mathrm{mg} / \mathrm{mL})$ and tocopherol standards were purchased from Matreya (Pleasant Gap, PA, USA). Fetal bovine serum (FBS), L-glutamine, Hank's balanced salt solution (HBSS), trypsin-ethylenediaminetetraacetic acid (EDTA), penicillin/streptomycin solution $(100 \mathrm{U} / \mathrm{mL}$ and $100 \mathrm{mg} / \mathrm{mL}$, respectively), RPMI-1640 and DMEM medium were obtained from Hyclone (Logan, Utah, USA). Tryptic Soy Broth (TSB) was obtained from Biomerieux (Marcy l'Etoile, France). Blood agar with 7\% sheep blood and MacConkey agar plates were purchased from Liofilchem (Roseto Degli Abruzzi, Italy). Other reagents and solvents of analytical grade were obtained from common sources. Water was treated with a Milli-Q water purification system (TGI Pure Water Systems, Greenville, SC, USA).

\subsection{Plant material}

Seeds of Cynara cardunculus L. var. altilis were collected in September 2018 from mature inflorescences of cardoon cultivated in Viseu, Portugal (CARDOP project). The seeds were air dried and separated according to their viability by immersion in distilled water as shown in Fig. 1A. Applying this widely used "float-testing", viable seeds stay fully immersed in water as a result of the higher weight caused by the presence of germen, while nonviable seeds (empty or without germen) stays floating in the surface (Himanen \& Nygren, 2015). Viable (Fig. 1B) and nonviable (Fig. 1C) seeds were then oven-dried (Jouan, Berlin, Germany) at $30{ }^{\circ} \mathrm{C}$ and reduced to a powder (20 mesh) for further analysis.

\subsection{Chromatographic analysis of chemical constituents}

\subsubsection{Tocopherols}

Hexane solutions of butyl-hydroxy-toluene $(10 \mathrm{mg} / \mathrm{mL} ; 100 \mu \mathrm{L})$ and tocol (internal standard (IS), $400 \mu \mathrm{L}$ at $50 \mu \mathrm{g} / \mathrm{mL}$ ) were added to the powdered seed samples $(500 \mathrm{mg}$ ) prior to extraction. The extraction was performed according to the procedure previously described by Pereira et al. (2014). The mixture was then homogenized with methanol $(4 \mathrm{~mL})$ by vortex mixing $(1 \mathrm{~min})$, followed by hexane $(4 \mathrm{~mL})$ (vortex mixed $-1 \mathrm{~min}$ ). After that, saturated $\mathrm{NaCl}$ aqueous solution $(2 \mathrm{~mL})$ was added, the mixture was homogenized (vortex $-1 \mathrm{~min}$ ), centrifuged ( $5 \mathrm{~min}, 4000 \mathrm{~g}$ ) and the clear upper layer was transferred to a vial. The sample extraction with hexane was performed three times. The combined extracts (clear layer) were taken to dryness under a nitrogen stream, dissolved in $n$-hexane $(2 \mathrm{~mL})$, dehydrated with anhydrous sodium sulphate, filtered through $0.2 \mu \mathrm{m}$ nylon filters, and transferred into a dark injection vial. The analysis was performed in a 
high performance liquid chromatography (HPLC, Knauer, Smartline system 1000, Berlin, Germany) system coupled to a fluorescence detector, following a procedure previously described (Pereira et al., 2014). The identification and quantification of tocopherols were performed using Clarity 2.4 software (DataApex, Podohradska, Czech Republic), by comparing the retention times with the spectra of commercial standards, using the internal standard method. The results were expressed in mg per $100 \mathrm{~g}$ of dry weight.

\subsubsection{Fatty acids}

The lipidic fraction was recovered with petroleum ether by Soxhlet extraction. After transesterification, fatty acids were analyzed in a DANI GC 1000 (DANI instruments, Contone, Switzerland) equipped with a split/splitless injector and a flame ionization detector (FID) at $260{ }^{\circ} \mathrm{C}$. The analytical procedures were previously described by Barros et al. (2013). The identification was made by chromatographic comparison of the retention times of the sample FAME peaks with those of the commercial standard. The results were processed using Clarity 2.4 software and expressed as relative percentage of each fatty acid.

\subsubsection{Organic acids}

The analysis of organic acids was performed in a ultra-fast liquid chromatography (UPLC) system coupled to a diode array detector (DAD), following a procedure described by Dias et al. (2015). For identification, the retention times and UV spectra of the sample peaks were compared with the ones of commercial standards, and the respective calibration curves were used for quantification based on the peak areas. The results were analysed using LabSolutions Multi LC-PDA software (Shimadzu Corporation, Kyoto, Japan) and expressed in $\mathrm{g}$ per $100 \mathrm{~g}$ of dry weight.

\subsubsection{Free sugars}

The free sugars content was determined according to the analytical conditions formerly described (Pereira et al., 2014). Samples were analysed in a HPLC system coupled to a refractive index detector (RI detector, Knauer Smartline 2300, Knauer, Berlin, Germany). The analysis of results was performed using Clarity 2.4 software. Quantification was performed by comparing the area of the sample peaks with calibration curves obtained from commercial sugar standards, using the internal standard method (IS, melezitose). The results were expressed in $\mathrm{g}$ per $100 \mathrm{~g}$ of dry weight.

\subsubsection{Analysis of phenolic compounds}

2.3.5.1. Extraction procedure. For preparation of extracts, each sample $(1.5 \mathrm{~g})$ was stirred $(150 \mathrm{rpm})$ with $\mathrm{MeOH} / \mathrm{H}_{2} \mathrm{O}(80: 20, v / v ; 30 \mathrm{~mL})$ for $1 \mathrm{~h}$ at room temperature. The supernatant was filtered through Whatman paper No. 4 and the residue was re-extracted under the same conditions. The obtained extracts were concentrated under reduced pressure (rotary evaporator Büchi R-210, Flawil, Switzerland) at $40{ }^{\circ} \mathrm{C}$ and the aqueous phase was frozen and lyophilized (FreeZone 4.5, Labconco, Kansas City, MO, USA).

2.3.5.2. HPLC-DAD-ESI/MS ${ }^{n}$ analysis. The dried extracts were redissolved in $\mathrm{MeOH} / \mathrm{H}_{2} \mathrm{O}(80: 20, v / v)$ to a concentration of $10 \mathrm{mg} / \mathrm{mL}$ and filtered through $0.22 \mu \mathrm{m}$ nylon syringe filters. The polyphenolic profile was determined by HPLC coupled to a diode array detector and electrospray ionization - mass spectrometry (HPLC-DAD-ESI/MS), according to a procedure previously described (Bessada, Barreira, Barros, Ferreira, \& Oliveira, 2016). The tentative identification was performed by comparison of the retention times and UV-Vis and mass spectra with those obtained from commercial standards and literature data. Quantification was performed by determination of the peak areas and chromatographic comparison with calibration curves (chlorogenic acid: $y=208604 x+173056, \mathrm{R}^{2}=0.9995 ; \mathrm{LOD}=0.20 \mu \mathrm{g} / \mathrm{mL}$; $\mathrm{LOQ}=0.68 \mu \mathrm{g} / \mathrm{mL}$ ) of commercial standards. The results were expressed in $\mathrm{mg}$ per $\mathrm{g}$ of extract.

\subsection{Evaluation of bioactive properties}

The hydromethanolic extracts of viable and nonviable cardoon seeds, prepared as described in 2.3.5.1., were used to evaluate the in vitro bioactive properties.

\subsubsection{Antioxidant activity}

The thiobarbituric acid reactive substances (TBARS) formation inhibition and oxidative haemolysis inhibition (OxHLIA) assays were performed to evaluate the antioxidant activity of the extracts. Trolox was used as a positive control.

TBARS assay. A porcine brain cell solution $(1: 2, w / v ; 0.1 \mathrm{~mL})$ was incubated with the extract solutions $(9.77-312.5 \mu \mathrm{g} / \mathrm{mL} ; 0.2 \mathrm{~mL})$ plus $\mathrm{FeSO}_{4}(10 \mu \mathrm{M} ; 0.1 \mathrm{~mL})$ and ascorbic acid $(0.1 \mathrm{mM} ; 0.1 \mathrm{~mL})$ at $37^{\circ} \mathrm{C}$ for $1 \mathrm{~h}$. Then, trichloroacetic ( $28 \% w / v, 0.5 \mathrm{~mL})$ and thiobarbituric (TBA, $2 \%, w / v, 0.38 \mathrm{~mL}$ ) acids were added and the mixture was heated at $80{ }^{\circ} \mathrm{C}$ for $20 \mathrm{~min}$. After centrifugation at $3000 \mathrm{~g}$ for $10 \mathrm{~min}$, the malondialdehyde (MDA)-TBA complexes formed in the supernatant were monitored at $532 \mathrm{~nm}$ (Specord 200 spectrophotometer, Analytik Jena, Jena, Germany) (Souilem et al., 2017). The results were expressed as $\mathrm{IC}_{50}$ values $(\mu \mathrm{g} / \mathrm{mL})$.

OxHLIA assay. An erythrocyte solution $(2.8 \%, v / v ; 200 \mu \mathrm{L})$ was mixed with $400 \mu \mathrm{L}$ of either extract solution (18.75-600 $\mu \mathrm{g} / \mathrm{mL}$ in PBS), PBS (control), or water (for complete haemolysis). After pre-incubation at $37{ }^{\circ} \mathrm{C}$ for $10 \mathrm{~min}$ with shaking, AAPH (200 $\mu \mathrm{L}, 160 \mathrm{mM}$ in PBS) was added and the optical density $(690 \mathrm{~nm})$ was measured every $10 \mathrm{~min}$ in a microplate reader (Bio-Tek Instruments Inc., ELX800, Winooski, VT, USA) until complete haemolysis (Mandim et al., 2019). The results were expressed as $\mathrm{IC}_{50}$ values $(\mu \mathrm{g} / \mathrm{mL})$ at $\Delta t$ of $60 \mathrm{~min}$ and $120 \mathrm{~min}$.

\subsubsection{Cytotoxicity and hepatotoxicity}

The cytotoxic activity of the extract solutions $(0.3906-400 \mu \mathrm{g} / \mathrm{mL}$ in water) was evaluated using the sulforhodamine B assay, according to the method previously described (Barros et al., 2013). Four human tumour cell lines (acquired from Leibniz-Institut DSMZ - Deutsche Sammlung von Mikroorganismen und Zellkulturen $\mathrm{GmbH}$, Braunschweig, Germany) were tested, namely: breast carcinoma (MCF7), nonsmall cell lung carcinoma (NCI-H460), cervical adenocarcinoma (HeLa), and hepatocellular carcinoma (HepG2), as well a non-tumour porcine liver primary culture (PLP2). Ellipticine was used as a positive control. The results were expressed in $\mathrm{GI}_{50}$ values $(\mu \mathrm{g} / \mathrm{mL})$.

\subsubsection{Anti-inflammatory activity}

The extracts capacity to inhibit the lipopolysaccharide (LPS)-induced NO production by a murine macrophage cell line (RAW 264.7) was determined as nitrite concentration in the culture medium as described previously (Mandim et al., 2019). Extracts re-dissolved in DMSO at a final concentration of $8 \mathrm{mg} / \mathrm{mL}$ were tested. Dexamethasone was used as a positive control, and negative controls were performed without LPS. The concentration that caused $50 \%$ of NO production inhibition was determined and expressed as $\mathrm{IC}_{50}$ values $(\mu \mathrm{g} / \mathrm{mL})$.

\subsubsection{Antimicrobial activity}

The extracts were re-dissolved in DMSO 5\% and further diluted to perform the assay as previously described (Petropoulos et al., 2019). To assess the antimicrobial activity, Gram-positive strains of Staphylococcus aureus (ATCC 6538), Bacillus cereus (clinical isolate), and Listeria monocytogenes (NCTC 7973), and Gram-negative strains of Escherichia coli (ATCC 25922), Salmonella enterica serovar Typhimurium (ATCC 13311), and Enterobacter cloacae (ATCC 35030) were tested. For the antifungal activity assay, the micromycetes Aspergillus niger (ATCC 6275), Aspergillus versicolor (ATCC11730), Penicillium funiculosum (ATCC 36839), Penicillium aurantiogriseum (Penicillium verrucosum var. cyclopium) (food isolate), Penicillium ochrochloron (ATCC 9112), and Trichoderma viride (IAM 5061) were tested following a methodology previously described (Petropoulos et al., 2019). The bacteria and fungi 
strains tested were obtained from the Mycological laboratory, Department of Plant Physiology, Institute for Biological research "Sinisa Stanković", University of Belgrade, Serbia. Sodium benzoate (E211) and potassium metabisulfite (E224) were used as positive controls. The results were given as minimum inhibitory (MIC) and minimum bactericidal $(\mathrm{MBC})$ or fungicidal (MFC) concentrations $(\mathrm{mg} / \mathrm{mL})$.

\subsection{Statistical analysis}

Three independent samples were assayed and the experiments were carried out in triplicate. The results were given as mean \pm standard deviation (except for antimicrobial activity). SPSS Statistics software (IBM SPSS Statistics for Windows, Version 22.0. Armonk, NY: IBM Corp.) was used to analyse differences among samples by applying a two-tailed paired Student's $t$-test at a 5\% significance level. Significant differences between the samples were considered when the $p$-value was lower than 0.05 .

\section{Results and discussion}

\subsection{Composition in tocopherols and fatty acids}

The results regarding the tocopherols composition of viable and unviable cardoon seeds are shown in Table 1. $\alpha$-Tocopherol was the only detected isoform, with the viable seeds presenting higher amounts $(6.7 \mathrm{mg} / 100 \mathrm{~g} \mathrm{dw})$ than the unviable ones $(3.0 \mathrm{mg} / 100 \mathrm{~g} \mathrm{dw})$. This result is in agreement with the findings of Petropoulos, Fernandes,

Table 1

Lipid fraction and tocopherol and fatty acid composition of C. cardunculus seeds.

\begin{tabular}{|c|c|c|c|}
\hline & Viable seeds & Unviable seeds & $p$-value* \\
\hline$\alpha$-Tocopherol (mg/100 g dw) & $6.7 \pm 0.3$ & $3.0 \pm 0.1$ & $<0.001$ \\
\hline Total lipid fraction ( $\mathrm{g} / 100 \mathrm{~g} \mathrm{dw}$ ) & $23.11 \pm 0.06$ & $8.9 \pm 0.3$ & $<0.001$ \\
\hline \multicolumn{4}{|l|}{ Fatty acids (\%) } \\
\hline C6:0 & $8.2 \pm 0.2$ & $5.1 \pm 0.1$ & $<0.001$ \\
\hline C8:0 & $1.5 \pm 0.1$ & $1.10 \pm 0.06$ & $<0.001$ \\
\hline C10:0 & $0.100 \pm 0.002$ & $0.065 \pm 0.001$ & $<0.001$ \\
\hline C12:0 & $0.02 \pm 0.01$ & $0.027 \pm 0.001$ & $<0.001$ \\
\hline C14:0 & $0.03 \pm 0.01$ & $0.39 \pm 0.01$ & $<0.001$ \\
\hline C15:0 & $0.100 \pm 0.01$ & $0.131 \pm 0.001$ & $<0.001$ \\
\hline C16:0 & $26.60 \pm 0.03$ & $31.8 \pm 0.7$ & $<0.001$ \\
\hline C16:1 & $0.21 \pm 0.01$ & $0.311 \pm 0.004$ & $<0.001$ \\
\hline $\mathrm{C} 17: 0$ & $0.162 \pm 0.004$ & $0.211 \pm 0.004$ & $<0.001$ \\
\hline C18:0 & $8.3 \pm 0.2$ & $8.8 \pm 0.4$ & 0.021 \\
\hline C18:1n9c & $48.70 \pm 0.01$ & $45 \pm 1$ & 0.001 \\
\hline $\mathrm{C} 18: 2 \mathrm{n} 6 \mathrm{c}$ & $3.2 \pm 0.2$ & $1.77 \pm 0.06$ & $<0.001$ \\
\hline C20:0 & $1.00 \pm 0.03$ & $1.25 \pm 0.04$ & $<0.001$ \\
\hline C20:1 & $0.231 \pm 0.004$ & $1.90 \pm 0.06$ & $<0.001$ \\
\hline C20:2 & $0.214 \pm 0.003$ & $0.13 \pm 0.01$ & $<0.001$ \\
\hline $\mathrm{C} 22: 0$ & $0.60 \pm 0.01$ & $0.60 \pm 0.04$ & 0.859 \\
\hline C22:1 & $0.156 \pm 0.001$ & $0.092 \pm 0.002$ & $<0.001$ \\
\hline $\mathrm{C} 20: 5 \mathrm{n} 3$ & $0.144 \pm 0.001$ & $0.190 \pm 0.001$ & $<0.001$ \\
\hline C23:0 & $0.047 \pm 0.002$ & $0.08 \pm 0.01$ & $<0.001$ \\
\hline $\mathrm{C} 24: 0$ & $0.457 \pm 0.002$ & $0.69 \pm 0.02$ & $<0.001$ \\
\hline SFA & $47.1 \pm 0.1$ & $50.3 \pm 0.9$ & 0.001 \\
\hline MUFA & $49.30 \pm 0.01$ & $47.7 \pm 0.9$ & 0.009 \\
\hline PUFA & $3.6 \pm 0.2$ & $2.08 \pm 0.05$ & $<0.001$ \\
\hline
\end{tabular}

Results are presented as mean \pm standard deviation. Fatty acids are expressed as relative percentage of each fatty acid. dw - dry weight; C6:0 - caproic acid; C8:0 - caprylic acid; C10:0 - capric acid; C12:0 - lauric acid; C14:0 - myristic acid; C15:0 - pentadecanoic acid; C16:0 palmitic acid; C16:1 - palmitoleic acid; C17:0 - heptadecanoic acid; C18:0 - stearic acid; C18:1n9c - oleic acid; C18:2n6c - linoleic acid; C20:0 - arachidic acid; C20:1 - gadoleic acid; C20:2 eicosadienoic acid; C22:0 - behenic acid; C22:1 - eicosenoic acid; C20:5n3 eicosapentaenoic acid; C23:0 - tricosanoic acid; C24:0 - lignoceric acid; SFA saturated fatty acids; MUFA - monounsaturated fatty acids; PUFA - polyunsaturated fatty acids. *Statistical differences $(p<0.05)$ were assessed by applying a two-tailed paired Student's $t$-test.
Pereira, et al. (2019) and Maccarone et al. (1999), who also reported $\alpha$ tocopherol as the only isoform in seeds (1.83-4.46 mg/100 g dw) and grain oils (25.1-54.6 mg/100 g) of different cardoon genotypes. Ferreira-Dias, Gominho, Baptista, and Pereira (2018) described the presence of three isoforms in cardoon seed oil, with $\alpha$-tocopherol in higher quantities (111.6-222.4 $\mathrm{mg} / \mathrm{kg}$ of oil) than the isoforms $\beta$ (67-98.2 mg/kg of oil) and $\gamma(1.2-5.2 \mathrm{mg} / \mathrm{kg}$ of oil). However, tocopherols are antioxidants susceptible to oxidation during post-harvest treatments, which can explain these differences.

The total lipid fraction and fatty acids profile of cardoon seeds are presented in Table 1. Viable seeds had 2.6 times more crude fat than nonviable seeds. In both samples, twenty fatty acids were identified, predominantly oleic acid (C18:1n9c; $48.7 \%$ and $45 \%$ in viable and unviable seeds, respectively), followed by palmitic (C16:0; $26.6 \%$ and $31.8 \%$, respectively) and by caproic (C6:0; $8.2 \%$ and $5.1 \%$, respectively) acids. In viable seeds, monounsaturated fatty acids (MUFA) were the most abundant (49.3\%), followed by saturated (SFA; $47.1 \%$ ) and polyunsaturated (PUFA; 3.6\%) fatty acids. In turn, in unviable seeds, it was found a predominance of SFA (50.3\%), followed by MUFA (47.7\%) and PUFA (2.1\%). These lower levels of unsaturated fatty acids in the unviable seeds may be due to oxidative reactions that may have occurred during their desiccation, as these fatty acids are those attacked by free radicals. As a result, cellular membranes can be injured and seeds damaged (Bailly, 2004; López-Fernández et al., 2018). In previous studies, Petropoulos, Fernandes, Pereira, et al. (2019) and Petropoulos, Pereira, Ntatsi, et al. (2018) described PUFA as predominant fatty acids in cardoon seeds and capitula, respectively, followed by SFA and MUFA, with linoleic (60.2-72.8\%) and oleic (10.9-19.4\%) acids as the most abundant ones.

It should be noted that studies on the chemical composition of cardoon seeds are scarce, since most of them aim to characterize their oil.

\subsection{Composition in organic acids and sugars}

The organic acids composition of the cardoon seeds is shown in Table 2. Oxalic, quinic, citric, and fumaric acids were identified and quantified in viable seeds, while oxalic and fumaric acids were not detected in unviable seeds. Quinic acid was detected in higher level, reaching $6.53 \mathrm{~g} / 100 \mathrm{~g} \mathrm{dw}$ in viable seeds and $5.98 \mathrm{~g} / 100 \mathrm{~g} \mathrm{dw}$ in unviable seeds. In general, viable seeds presented a higher amount $(6.54 \mathrm{~g} / 100 \mathrm{~g} \mathrm{dw})$ of organic acids than unviable seeds $(5.98 \mathrm{mg} / 100 \mathrm{~g}$ dw). In a previous study of Petropoulos, Fernandes, Pereira, et al. (2019), oxalic acid (143-304 mg/100 g dw) was the only organic acid quantified in cardoon seed of different genotypes, and traces of malic and fumaric acids were also detected.

Regarding free sugars (Table 2), viable seeds contained fructose, glucose, and sucrose. Sucrose was found in higher concentrations

Table 2

Organic acid and free sugar composition of $C$. cardunculus seeds.

\begin{tabular}{|c|c|c|c|}
\hline & Viable seeds & Unviable seeds & $p$-value* \\
\hline \multicolumn{4}{|c|}{ Organic acids $(g / 100 \mathrm{~g} \mathrm{dw})$} \\
\hline Oxalic acid & $0.0055 \pm 0.0003$ & nd & - \\
\hline Quinic acid & $6.53 \pm 0.03$ & $5.98 \pm 0.07$ & $<0.001$ \\
\hline Citric acid & $0.0033 \pm 0.0002$ & $\operatorname{tr}$ & - \\
\hline Fumaric acid & $\operatorname{tr}$ & nd & - \\
\hline Total organic acids & $6.54 \pm 0.03$ & $5.98 \pm 0.07$ & $<0.001$ \\
\hline \multicolumn{4}{|c|}{ Free sugars $(g / 100 g d w)$} \\
\hline Fructose & $1.94 \pm 0.01$ & nd & - \\
\hline Glucose & $0.78 \pm 0.04$ & nd & - \\
\hline Sucrose & $2.64 \pm 0.02$ & $0.51 \pm 0.04$ & $<0.001$ \\
\hline Total free sugars & $5.4 \pm 0.1$ & $0.51 \pm 0.04$ & $<0.001$ \\
\hline
\end{tabular}

Results are presented as mean \pm standard deviation. dw - dry weight; $\mathrm{tr}$ traces; nd - not detected. *Statistical differences $(p<0.05)$ were assessed by applying a two-tailed paired Student's $t$-test. 
Table 3

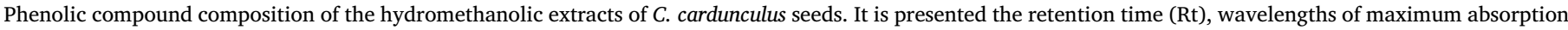
$\left(\lambda_{\max }\right)$ in the UV-vis region, and mass spectral data used in the tentative identification of phenolic compounds.

\begin{tabular}{|c|c|c|c|c|c|c|c|c|}
\hline \multirow[t]{2}{*}{ Peak } & \multirow[t]{2}{*}{ Rt (min) } & \multirow[t]{2}{*}{$\lambda \max (\mathrm{nm})$} & \multirow[t]{2}{*}[\mathrm{M}-\mathrm{H}]{$^{-}(m / z)$} & \multirow[t]{2}{*}{$\operatorname{MS}^{2}(m / z)$} & \multirow[t]{2}{*}{ Tentative identification } & \multicolumn{2}{|c|}{ Content (mg/g extract) } & \multirow[t]{2}{*}{$p$-value* } \\
\hline & & & & & & Viable & Unviable & \\
\hline 1 & 7.09 & 325 & 353 & 191(100), 179(10), 161(5), 135(5) & 5-O-Caffeoylquinic acid & $8.0 \pm 0.1$ & $3.91 \pm 0.05$ & $<0.001$ \\
\hline \multirow[t]{2}{*}{2} & 20.14 & 324 & 515 & 353(50), 191(100), 179(15), 173(5), 135(5) & 3,5-O-Dicaffeoylquinic acid & $43.9 \pm 0.8$ & $13.8 \pm 0.1$ & $<0.001$ \\
\hline & & & & & $\Sigma$ Phenolic compounds & $51.9 \pm 0.9$ & $17.72 \pm 0.06$ & $<0.001$ \\
\hline
\end{tabular}

Results are presented as mean \pm standard deviation. *Statistical differences $(p<0.05)$ were assessed by applying a two-tailed paired Student's $t$-test.

$(2.64 \mathrm{~g} / 100 \mathrm{~g} \mathrm{dw})$, followed by fructose $(1.94 \mathrm{~g} / 100 \mathrm{~g} \mathrm{dw})$ and glucose $(0.78 \mathrm{~g} / 100 \mathrm{~g} \mathrm{dw})$. In unviable seeds only sucrose was quantified $(0.51 \mathrm{~g} / 100 \mathrm{~g} \mathrm{dw})$. Thus, the total sugar content in viable seeds was $\sim 10.6$ times higher than in unviable seeds. Petropoulos, Fernandes, Pereira, et al. (2019) only described sucrose (0.30-0.51 g/ $100 \mathrm{~g} \mathrm{dw}$ ) in cardoon seeds.

Sugars and organic acids are known to be involved in seed development (Mazlan, Aizat, Baharum, Azizan, \& Noor, 2018) and the contents reported in this study can be related to the seeds quality and viability status. Thus, with soluble sugars as reserve, cardoon seed will have immediate energy and carbon source ready for germination.

\subsection{Composition in phenolic compounds}

The chromatographic data (retention time, $\lambda_{\max }$ in the UV-vis region, pseudomolecular ion, and fragmentation pattern) regarding the identification and quantification of phenolic compounds in the hydromethanolic extracts of $C$. cardunculus seeds are presented in Table 3. Only two caffeoylquinic acid derivatives were found in the seed extracts. Peak 1 was tentatively identified as 5 -O-caffeoylquinic acid according to its UV spectrum, pseudomolecular ion, and main fragment ions in comparison with the commercial standard (chlorogenic acid). Peak $2\left([\mathrm{M}-\mathrm{H}]^{-}\right.$at $\left.\mathrm{m} / \mathrm{z} 515\right)$ was assigned to 3,5-O-dicaffeoylquinic acid taking into account the hierarchical fragmentation pattern previously reported by Clifford, Johnston, Knight, and Kuhnert (2003, 2005). In both cases, the major product ion detected was observed at $\mathrm{m} / \mathrm{z} 191$ and identified as quinic acid, which is formed by cleavage of the ester bond between the quinic and caffeic acid moieties. The different phenolic content between the two samples is evident, especially with regard to 3,5-O-dicaffeoylquinic acid (levels ranging from $13.8 \mathrm{mg} / \mathrm{g}$ unviable seed extract to $43.9 \mathrm{mg} / \mathrm{g}$ viable seed extract). Additionally, the total content of phenolic compounds was $\sim 2.9$ times higher in viable seeds. This type of hydroxycinnamic acids was previously reported in different parts of $C$. cardunculus, namely in inflorescences from samples grown in Portugal (Dias et al., 2018), flower heads, leaf blades, leaf midribs, and petioles (Petropoulos, Pereira, Tzortzakis, et al., 2018), and also seeds from different genotypes cultivated in central Greece (Petropoulos et al., 2019). As secondary metabolites, the presence of phenolic compounds was expected to be more evident in tissues with a higher viability. According to Rendón, De Jesus Garcia Salva, and Bragagnolo (2014), seeds ageing and viability loss may be related not only to lipid and protein oxidation, but also to decrease in 5-O-caffeoylquinic acid levels.

\subsection{Bioactive properties}

\subsubsection{Antioxidant activity}

The results of the cell-based antioxidant activity assay are presented in Table 4. It is given the extract concentration needed to protect $50 \%$ of the erythrocyte from the haemolytic action caused by the oxidizing agent for 60 and $120 \mathrm{~min}$ or to provide $50 \%$ of antioxidant activity in OxHLIA and TBARS, respectively. The lower the $\mathrm{IC}_{50}$ values, the higher the antioxidant capacity. Viable seed extract was the most bioactive in both tests, with the lowest IC $_{50}$ values of $17.3 \mu \mathrm{g} / \mathrm{mL}$ in TBARS and 79 and $148 \mu \mathrm{g} / \mathrm{mL}$ in OxHLIA for $\Delta t$ of 60 and $120 \mathrm{~min}$, respectively. However, these $\mathrm{IC}_{50}$ values are about 1.9, 4.0, and 3.6 times higher than those of the positive control, trolox (Table 4). The unviable seed extract revealed lower antioxidant potential, especially in the TBARS assay. Thus, this extract was less effective in inhibiting the formation of malondialdehyde and other reactive substances that are generated from the decomposition of lipid peroxidation products. Porcine brain cells were used for this purpose because they are biological substrates rich in polyunsaturated fatty acids.

The antioxidant potential of cardoon is widely described in the literature, especially its free radical scavenging capacity as measured by the DPPH assay. Some authors also reported that certain parameters can affect the antioxidant capacity of cardoon, such as genetic variation, analysed plant tissue, and extraction method used to obtain the extract. Significant differences in the antioxidant activity were already detected between cardoon seeds of different genotypes (Petropoulos et al., 2019). It has also been reported that seed extracts exhibit higher antioxidant activity than other cardoon parts, such as leaf blades, flowers (Petropoulos, Pereira, Tzortzakis et al., 2018), and leaves (Georgieva et al., 2014). These differences could be related to the presence of specific polyphenols, as well as other bioactive molecules, such as saponins and tannins. Growing conditions, cultivation practices and the geographical location may also affect the antioxidant capacity of cardoon (Petropoulos et al., 2018). To the best of the authors' knowledge, this is the first study comparing the antioxidant activity of viable and unviable cardoon seeds and measuring their (antihaemolytic) activity by OxHLIA. A correlation between the content of phenolic compounds and antioxidant properties has been demonstrated (Mandim et al., 2019; Palmeira et al., 2019; Petropoulos, Fernandes, et al., 2018). Herein, viable seeds revealed higher levels of phenolic compounds and $\alpha$-tocopherol and a higher antioxidant capacity, thus suggesting a positive correlation between these parameters.

\subsubsection{Cytotoxic activity}

The cytotoxic activity of the cardoon seed extracts against four human tumour cell lines and a primary liver cell line was tested and the results are presented in Table 4. None of the extracts revealed cytotoxic potential against lung, breast, liver, or cervical tumour cells at the tested concentrations ( $\mathrm{GI}_{50}$ values $>400 \mu \mathrm{g} / \mathrm{mL}$ ). Furthermore, the extracts had no hepatotoxicity to the non-tumour PLP2 cells, with $\mathrm{GI}_{50}$ values $>400 \mu \mathrm{g} / \mathrm{mL}$. These results are in agreement with those of Petropoulos, Fernandes, Pereira, et al. (2019), who found that, among several genotypes of this plant, only a few have cytotoxic potential against the same cell lines (with $\mathrm{GI}_{50}$ values between 212 and > $400 \mu \mathrm{g} / \mathrm{mL}$ ). The absence of toxicity to non-tumour cell lines has also been reported by other authors (Mileo, Di Venere, Linsalata, Fraioli, \& Miccadei, 2012; Petropoulos, Pereira, Tzortzakis, et al., 2018; Petropoulos et al., 2019).

\subsubsection{NO-production inhibition capacity}

NO is a proinflammatory mediator produced by inducible nitric oxide synthase (iNOS), and plays an important role in the inflammatory process (Aktan, 2004). To measure the inhibitory effects of the extracts against the inflammatory response, a cell-based screening bioassay to 
Table 4

Antioxidant, cytotoxic and anti-inflammatory activities of $C$. cardunculus seed extracts.

\begin{tabular}{|c|c|c|c|c|}
\hline & Viable seeds & Unviable seeds & Positive control & $p$-value* \\
\hline Antioxidant activity $\left(I C_{50}, \mu \mathrm{g} / \mathrm{mL}\right)$ & & & Trolox & \\
\hline TBARS & $17.0 \pm 0.1$ & $48 \pm 1$ & $9.1 \pm 0.3$ & $<0.001$ \\
\hline OxHLIA, $\Delta t=60 \mathrm{~min}$ & $79 \pm 4$ & $93 \pm 3$ & $21.2 \pm 0.7$ & $<0.001$ \\
\hline OxHLIA, $\Delta t=120 \mathrm{~min}$ & $148 \pm 7$ & $160 \pm 9$ & $41.1 \pm 0.8$ & $<0.001$ \\
\hline Cytotoxic activity $\left(\mathrm{GI}_{50}, \mu \mathrm{g} / \mathrm{mL}\right)$ & & & Ellipticine & \\
\hline MCF-7 (breast adenocarcinoma) & $>400$ & $>400$ & $1.21 \pm 0.02$ & - \\
\hline NCI-H460 (lung carcinoma) & $>400$ & $>400$ & $0.91 \pm 0.11$ & - \\
\hline HeLa (cervical adenocarcinoma) & $>400$ & $>400$ & $1.03 \pm 0.09$ & - \\
\hline HepG2 (hepatocellular carcinoma) & $>400$ & $>400$ & $1.10 \pm 0.09$ & - \\
\hline PLP2 (porcine liver primary cells) & $>400$ & $>400$ & $2.29 \pm 0.18$ & - \\
\hline NO-production inhibition $\left(I C_{50}, \mu \mathrm{g} / \mathrm{mL}\right)$ & & & Dexamethasone & \\
\hline RAW 246.7 (murine macrophage cells) & $>400$ & $>400$ & $16 \pm 1$ & - \\
\hline
\end{tabular}

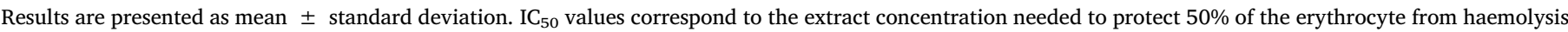

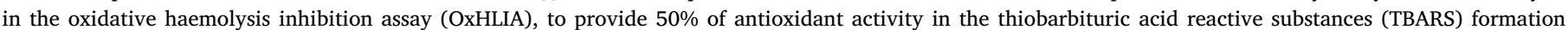

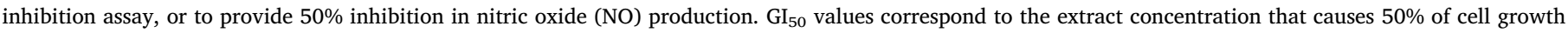
inhibition. *Statistical differences $(p<0.05)$ between viable and unviable seeds were assessed by applying a two-tailed paired Student's $t$-test.

test the NO level in LPS-stimulated RAW 264.7 macrophages was performed. Given the importance of NO in inflammatory processes, the search for new substances that can inhibit its production has been an active field of research. As shown in Table 4, none of the tested extracts revealed capacity to inhibit the NO production at the tested concentrations, as $\mathrm{IC}_{50}$ values greater than $400 \mu \mathrm{g} / \mathrm{mL}$ were obtained. Studies regarding the anti-inflammatory potential of cardoon are very scarce. To the best of the authors' knowledge, this is the first study reporting the evaluation of the anti-inflammatory potential of cardoon seeds through this cell-based assay. Kammoun et al. (2010) tested the anti-inflammatory potential of $C$. cardunculus leaf and stem extracts by measuring their inhibition potential of mammalian non-pancreatic phospholipases A2 (hG-IIA) and found that leaf extracts exhibited potent hG-IIA inhibition, higher than that of stem extracts.

\subsubsection{Antimicrobial activity}

Different parts of cardoon have been used as antimicrobial agents in traditional medicine. For this reason, the seed extracts were tested for their antibacterial and antifungal potential. Six Gram-positive and Gram-negative bacteria and six fungi were screened, and the results expressed as MIC, MFC, and MFC values $(\mathrm{mg} / \mathrm{mL})$ are presented in Table 5. Regarding the antibacterial potential, both extracts had bacteriostatic and bactericidal activity for some of the tested microorganisms similar to that of the used positive controls. In general, unviable seeds originated the best results, with almost all MIC and MBC values equal to those of sodium benzoate (E211, a food preservative used as positive control), except for Salmonella enterica serovar Typhimurium, which is a worldwide major cause of bacterial foodborne diseases that required a higher extract concentration to be inhibited or killed (Table 5). This extract also gave a MIC $(2 \mathrm{mg} / \mathrm{mL})$ and an MBC $(1 \mathrm{mg} /$ $\mathrm{mL}$ ) lower to that of E211 and potassium metabisulfite (E224) for Staphylococcus aureus and Bacillus cereus, respectively. The tested Grampositive bacteria appeared to be more sensitive to the tested extracts than Gram-negative bacteria probably because the abundant peptidoglycan is not protected by an outer membrane. Furthermore, the lipopolysaccharide cell wall of Gram-negative bacteria may block the penetration of certain compounds and prevent their accumulation in the target cell membranes. This observation agrees with previous reports indicating that Gram-positive bacteria are more sensitive to plant extracts (Gyawali, Hayek, \& Ibrahim, 2014). In Table 5 it is also possible to observe that the two cardoon seed extracts had equal antibacterial activity against Listeria monocytogenes and Enterobacter cloacae, with identical MIC and MBC values. Moreover, the positive control E224 was most active against the tested bacteria than E211.

The antifungal potential of the cardoon seeds extracts against Aspergillus spp., Penicillium spp., and Trichoderma viride was also assessed. As presented in Table 5, the tested extracts originated higher MIC and MFC values than the positive controls E211 and E224. Both extracts had similar antifungal activity, with equal MIC and MFC values for all fungi except Penicillium aurantiogriseum. For this species, viable

Table 5

Antibacterial and antifungal activities of $C$. cardunculus seed extracts.

\begin{tabular}{|c|c|c|c|c|c|c|c|c|}
\hline \multirow[b]{2}{*}{ Antibacterial activity $(\mathrm{mg} / \mathrm{mL})$} & \multicolumn{2}{|c|}{ Viable seeds } & \multicolumn{2}{|c|}{ Unviable seeds } & \multicolumn{2}{|l|}{ E211 } & \multicolumn{2}{|c|}{ E224 } \\
\hline & MIC & MBC & MIC & MBC & MIC & MBC & MIC & MBC \\
\hline Staphylococcus aureus & 4 & 8 & 2 & 4 & 4 & 4 & 1 & 1 \\
\hline Bacillus cereus & 2 & 4 & 0.5 & 1 & 0.5 & 0.5 & 2 & 4 \\
\hline Listeria monocytogenes & 1 & 2 & 1 & 2 & 1 & 2 & 0.5 & 1 \\
\hline Escherichia coli & 2 & 4 & 1 & 2 & 1 & 2 & 0.5 & 1 \\
\hline Salmonella enterica ser. Typhimurium & 4 & 8 & 2 & 4 & 1 & 2 & 1 & 1 \\
\hline Enterobacter cloacae & 2 & 4 & 2 & 4 & 2 & 4 & 0.5 & 0.5 \\
\hline Antifungal activity (mg/mL) & MIC & MFC & MIC & MFC & MIC & MFC & MIC & MFC \\
\hline Aspergillus niger & 4 & 8 & 4 & 8 & 1 & 2 & 1 & 1 \\
\hline Aspergillus versicolor & 4 & 8 & 4 & 8 & 2 & 2 & 1 & 1 \\
\hline Penicillium funiculosum & 4 & 8 & 4 & 8 & 1 & 2 & 0.5 & 0.5 \\
\hline Penicillium aurantiogriseum & 8 & $>8$ & $>8$ & $>8$ & 2 & 4 & 1 & 1 \\
\hline Penicillium ochrochloron & 8 & $>8$ & 8 & $>8$ & 2 & 4 & 0.5 & 1 \\
\hline Trichoderma viride & 4 & 8 & 4 & 8 & 1 & 2 & 0.5 & 0.5 \\
\hline
\end{tabular}

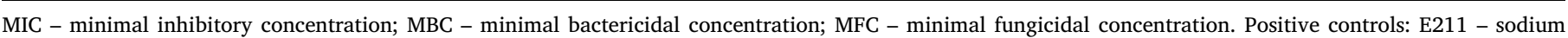
benzoate; and E224 - potassium metabisulfite. 
seeds gave a lower MIC $(8 \mathrm{mg} / \mathrm{mL})$ than unviable seeds ( $>8 \mathrm{mg} / \mathrm{mL})$. In a previous study (Petropoulos et al., 2019), lower MIC and MFC values were reported for Aspergillus niger, Penicillium ochrochloron, and Penicillium verrucosum var. cyclopium. These variations can be related to genetic variations, which may influence the chemical composition and, consequently, the antimicrobial activity of cardoon seeds (Petropoulos et al., 2019) and inflorescences (Dias et al., 2018), but also with the edaphoclimatic condition of the geographic locations where the samples were grown. According to other reports (Falleh et al., 2008; Scavo et al., 2019), different cardoon tissues (namely flower heads, flowers, leaves, and rhizomes) show significant antimicrobial activity against various bacteria (Staphylococcus aureus, Bacillus cereus, Pseudomonas aeruginosa, Escherichia coli, Salmonella enterica, and Pseudomonas fluorescens) and fungi (Aspergillus niger, Candida albicans, and Penicillium oxalicum) species.

Overall, the differences in the in vitro bioactivities of the tested extracts discussed above showed that viability is a trait that influences the biological potential of cardoon seeds.

\section{Conclusion}

Viable cardoon seeds contained higher levels of $\alpha$-tocopherol, MUFA (mostly oleic acid), PUFA (such as linoleic acid) and free sugars (including sucrose) than the unviable ones. Extracts prepared from viable seeds also contained higher amounts of phenolic compounds, namely 5-O-caffeoylquinic acid and manly 3,5-O-dicaffeoylquinic acid, and a higher antioxidant activity, translated by lower IC $_{50}$ values in both in vitro cell-based assays. On the other hand, although the seed extracts had bacteriostatic and bactericidal activities against some of the tested bacteria similar to those of the used positive controls, the unviable seed extract generally originated the best results, with almost all MIC and MBC values equal to those of sodium benzoate. Regarding antifungal activity, both extracts led to similar results. However, none of the extracts showed anti-inflammatory and cytotoxic activities at the tested concentrations. Therefore, cardoon seeds may be used to obtain bio-based ingredients with bioactive characteristics.

\section{CRediT authorship contribution statement}

Filipa Mandim: Conceptualization, Methodology, Investigation, Formal analysis, Writing - original draft. Maria Inês Dias: Methodology, Investigation, Writing - original draft. José Pinela: Methodology, Investigation, Writing - original draft, Writing - review \& editing. Paulo Barracosa: Investigation, Writing - review \& editing. Marija Ivanov: Methodology, Investigation. Dejan Stojković: Methodology, Investigation. Marina Soković: Investigation, Resources, Validation. Celestino Santos-buelga: Validation, Writing - review \& editing. Lillian Barros: Conceptualization, Supervision, Validation, Writing - review \& editing. Isabel C.F.R. Ferreira: Conceptualization, Resources, Validation, Writing - review \& editing.

\section{Declaration of Competing Interest}

The authors declare that they have no known competing financial interests or personal relationships that could have appeared to influence the work reported in this paper.

\section{Acknowledgements}

The authors are grateful to the Foundation for Science and Technology (FCT, Portugal) for financial support by national funds FCT/MCTES to CIMO (UIDB/00690/2020). National funding by FCT, through the institutional scientific employment program-contract with M.I. Dias, J. Pinela and L. Barros. To FCT for the PhD grant (SFRH/BD/ $146614 / 2019)$ of F. Mandim. The authors are also grateful to FEDER-
Interreg España-Portugal programme for financial support through the project 0377_Iberphenol_6_E, to the project TRANSCoLAB (0612_TRANS_CO_LAB_2_P), and to the Ministry of Education, Science and Technological Development of the Republic of Serbia for Grant No. 173032. The authors are grateful to Manuela Antunes from Cynatura for the seed recollection.

\section{References}

Aktan, F. (2004). iNOS-mediated nitric oxide production and its regulation. Life Sciences, 75(6), 639-653.

Bailly, C. (2004). Active oxygen species and antioxidants in seed biology. Seed Science Research, 14(2), 93-107.

Barracosa, P., Rosa, N., Barros, M., \& Pires, E. (2018). Selected cardoon (Cynara car dunculus L.) genotypes suitable for PDO cheeses in Mediterranean regions. Chemistry and Biodiversity, 15, e1800110.

Barros, L., Pereira, E., Calhelha, R. C., Dueñas, M., Carvalho, A. M., Santos-Buelga, C., \& Ferreira, I. C. F. R. (2013). Bioactivity and chemical characterization in hydrophilic and lipophilic compounds of Chenopodium ambrosioides L. Journal of Functional Foods, 5(4), 1732-1740.

Bessada, S. M. F., Barreira, J. C. M., Barros, L., Ferreira, I. C. F. R., \& Oliveira, M. B. P. P. (2016). Phenolic profile and antioxidant activity of Coleostephus myconis (L.) Rchb.f.: An underexploited and highly disseminated species. Industrial Crops and Products, 89, 45-51.

Clifford, M. N., Johnston, K. L., Knight, S., \& Kuhnert, N. (2003). Hierarchical scheme for LC-MS ${ }^{\mathrm{n}}$ identification of chlorogenic acids. Journal of Agricultural and Food Chemistry, 51(10), 2900-2911.

Clifford, M. N., Knight, S., \& Kuhnert, N. (2005). Discriminating between the six isomers of dicaffeoylquinic acid by LC-MS ${ }^{\mathrm{n}}$. Journal of Agricultural and Food Chemistry, 53(10), 3821-3832.

de Falco, B., Incerti, G., Amato, M., \& Lanzotti, V. (2015). Artichoke: Botanical, agronomical, phytochemical, and pharmacological overview. Phytochemistry Reviews, 14(6), 993-1018.

Dias, M. I., Barros, L., Barreira, J. C. M., Alves, M. J., Barracosa, P., \& Ferreira, I. C. F. R. (2018). Phenolic profile and bioactivity of cardoon (Cynara cardunculus L.) inflorescence parts: Selecting the best genotype for food applications. Food Chemistry, 268, 196-202.

Dias, M. I., Barros, L., Morales, P., Sánchez-Mata, M. C., Oliveira, M. B. P. P., \& Ferreira, I. C. F. R. (2015). Nutritional parameters of infusions and decoctions obtained from Fragaria vesca L. roots and vegetative parts. LWT - Food Science and Technology, 62(1), 32-38.

Falleh, H., Ksouri, R., Chaieb, K., Karray-Bouraoui, N., Trabelsi, N., Boulaaba, M., \& Abdelly, C. (2008). Phenolic composition of Cynara cardunculus L. organs, and their biological activities. Comptes Rendus - Biologies, 331(5), 372-379.

FAO (2019). Cardoon | FAO | Food and Agriculture Organization of the United Nations. Retrieved November 7, 2019, from http://www.fao.org/traditional-crops/cardoon/ en/.

Fernández, J., Curt, M. D., \& Aguado, P. L. (2006). Industrial applications of Cynara cardunculus L. for energy and other uses. Industrial Crops and Products, 24(3), 222-229.

Ferreira-Dias, S., Gominho, J., Baptista, I., \& Pereira, H. (2018). Pattern recognition of cardoon oil from different large-scale field trials. Industrial Crops and Products, 118, $236-245$.

Georgieva, E., Karamulakova, Y., Nikokova, G., Grigorov, B., Pavlov, D., Gadjeva, V., \& Zheleva, A. (2014). Radical scavenging capacity of seeds and leaves ethanol extracts of Cynara scolymus L. - A comparative study. Pharmaceutical Biotechnology, 26, $151-155$.

Gominho, J., Curt, M. D., Lourenço, A., Fernández, J., \& Pereira, H. (2018). Cynara cardunculus L. as a biomass and multi-purpose crop: A review of 30 years of research. Biomass and Bioenergy, 109, 257-275.

Gyawali, R., Hayek, S. A., \& Ibrahim, S. A. (2014). Plant extracts as antimicrobials in food products: Mechanisms of action, extraction methods, and applications. Handbook of Natural Antimicrobials for Food Safety and Quality (pp. 49-68). Elsevier Ltd.

Himanen, K., \& Nygren, M. (2015). Seed soak-sorting prior to sowing affects the size and quality of 1.5-year-old containerized Picea abies seedlings. Silva Fennica, 49(3), 1-15.

Kammoun, M., Koubaa, I., Ali, Y. Ben, Jarraya, R., Gargouri, Y., Damak, M., \& Bezzine, S. (2010). Inhibition of pro-inflammatory secreted phospholipase A2 by extracts from Cynara cardunculus L. Applied Biochemistry and Biotechnology, 162, 662-670.

López-Fernández, M. P., Moyano, L., Correa, M. D., Vasile, F., Burrieza, H. P., \& Maldonado, S. (2018). Deterioration of willow seeds during storage. Scientific Reports, 8(1), 17207.

Maccarone, E., Fallico, B., Fanella, F., Mauromicale, G., Raccuia, S. A., \& Foti, S. (1999). Possible alternative utilization of Cynara spp. II. Chemical characterization of their grain oil. Industrial Crops and Products, 10, 229-237.

Mandim, F., Barros, L., Calhelha, R. C., Abreu, R. M. V., Pinela, J., Alves, M. J., ... Ferreira, I. C. F. R. (2019). Calluna vulgaris (L.) Hull: Chemical characterization, evaluation of its bioactive properties and effect on the vaginal microbiota. Food and Function, 10, $78-89$.

Mauromicale, G., Sortino, O., Pesce, G. R., Agnello, M., \& Mauro, R. P. (2014). Suitability of cultivated and wild cardoon as a sustainable bioenergy crop for low input cultivation in low quality Mediterranean soils. Industrial Crops and Products, 57, 82-89.

Mazlan, O., Aizat, W. M., Baharum, S. N., Azizan, K. A., \& Noor, N. M. (2018), Metabolomics analysis of developing Garcinia mangostana seed reveals modulated 
levels of sugars, organic acids and phenylpropanoid compounds. Scientia Horticulturae, 233, 323-330.

Mileo, A. M., Di Venere, D., Linsalata, V., Fraioli, R., \& Miccadei, S. (2012). Artichoke polyphenols induce apoptosis and decrease the invasive potential of the human breast cancer cell line MDA-MB231. Journal of Cellular Physiology, 227(9), 3301-3309. https://doi.org/10.1002/jcp.24029.

Palmeira, L., Pereira, C., Dias, M. I., Abreu, R. M. V., Corrêa, R. C. G., Pires, T. C. S. P., ... Ferreira, I. C. F. R. (2019). Nutritional, chemical and bioactive profiles of different parts of a Portuguese common fig (Ficus carica L.) variety. Food Research International, 126,108572

Pereira, E., Barros, L., Calhelha, R. C., Dueñas, M., Carvalho, A. M., Santos-Buelga, C., \& Ferreira, I. C. F. R. (2014). Bioactivity and phytochemical characterization of Arenaria montana L. Food \& Function, 5(8), 1848-1855.

Petropoulos, S. A., Fernandes, Â., Pereira, C., Tzortzakis, N., Vaz, J., Soković, M., ... Ferreira, I. C. F. R. (2019). Bioactivities, chemical composition and nutritional value of Cynara cardunculus L. seeds. Food Chemistry, 289, 404-412.

Petropoulos, S. A., Fernandes, Â., Tzortzakis, N., Sokovic, M., Ciric, A., Barros, L., \& Ferreira, I. C. F. R. (2019). Bioactive compounds content and antimicrobial activities of wild edible Asteraceae species of the Mediterranean flora under commercial cultivation conditions. Food Research International, 119, 859-868.

Petropoulos, S. A., Pereira, C., Ntatsi, G., Danalatos, N., Barros, L., \& Ferreira, I. C. F. R. (2018). Nutritional value and chemical composition of Greek artichoke genotypes. Food Chemistry, 267, 296-302.

Petropoulos, S. A., Pereira, C., Tzortzakis, N., Barros, L., \& Ferreira, I. C. F. R. (2018). Nutritional value and bioactive compounds characterization of plant parts from Cynara cardunculus L. (Asteraceae) cultivated in central Greece. Frontiers Plant Science, 9, 459.
Piluzza, G., Molinu, M. G., Re, G. A., \& Sulas, L. (2019). Phenolic compounds content and antioxidant capacity in cardoon achenes from different head orders. Natural Product Research, 5, 1-5.

Raccuia, Salvatore Antonino, \& Melilli, M. G. (2010). Seasonal dynamics of biomass, inulin, and water-soluble sugars in roots of Cynara cardunculus L. Field Crops Research, 116(1-2), 147-153.

Ramos, P. A. B., Guerra, Â. R., Guerreiro, O., Santos, S. A. O., Oliveira, H., Freire, C. S. R., ... Duarte, M. F. (2017). Antiproliferative effects of Cynara cardunculus L. var. altilis (DC) lipophilic extracts. International Journal of Molecular Sciences, 18, 63.

Rendón, M. Y., De Jesus Garcia Salva, T., \& Bragagnolo, N. (2014). Impact of chemical changes on the sensory characteristics of coffee beans during storage. Food Chemistry, 147, 279-286.

Scavo, A., Pandino, G., Restuccia, C., Parafati, L., Cirvilleri, G., \& Mauromicale, G. (2019). Antimicrobial activity of cultivated cardoon (Cynara cardunculus L. var. altilis DC.) leaf extracts against bacterial species of agricultural and food interest. Industrial Crops and Products, 129, 206-211.

Souilem, F., Fernandes, Â., Calhelha, R. C., Barreira, J. C. M., Barros, L., Skhiri, F., .. Ferreira, I. C. F. R. (2017). Wild mushrooms and their mycelia as sources of bioactive compounds: Antioxidant, anti-inflammatory and cytotoxic properties. Food Chemistry, $230,40-48$.

Vergara, P., Ladero, M., García-Ochoa, F., \& Villar, J. C. (2018). Valorization of Cynara Cardunculus crops by ethanol-water treatment: Optimization of operating conditions. Industrial Crops and Products, 124, 856-862.

Xia, Y., Xu, Y., Li, J., Zhang, C., \& Fan, S. (2019). Recent advances in emerging techniques for non-destructive detection of seed viability: A review. Artificial Intelligence in Agriculture, 1, 35-47. 